\title{
Inter-connected coupled lines resonator topology for bandpass filter application
}

\author{
Mohd Nasiruddin Hushim¹, Norfishah Ab Wahab ${ }^{2}$, Tn. Syarifah Atifah Tn. Mat Zin ${ }^{3}$, Norlia Ghazali ${ }^{4}$ \\ ${ }^{1,2}$ Faculty of Electrical Engineering, Universiti Teknologi MARA, Malaysia \\ ${ }^{3,4}$ Department of Mathematics, Science and Computer, Politeknik Banting Selangor, Malaysia
}

\begin{tabular}{|c|c|}
\hline Article Info & ABSTRACT \\
\hline Article history: & \multirow{10}{*}{$\begin{array}{l}\text { This paper presents an inter-connected side-shorted coupled-line resonator } \\
\text { topology as a base cell. The base cell is built from two single-shorted } \\
\text { quarter-wavelength coupled-line sections, connected in series to give a half- } \\
\text { wavelength coupled-line that creates a single resonance of bandpass filter } \\
\text { response. Higher-order bandpass filter is produced by adding new single- } \\
\text { shorted coupled-line sections, cascaded in an inter-connected manner to } \\
\text { the base cell. This new topology creates a unique arrangement that caused } \\
\text { cross coupling effects between the resonators, resulting to the occurrence of } \\
\text { transmission zeros that lead to the improvement of selectivity of the higher } \\
\text { order bandpass filter response. For validation of concept, } 2^{\text {nd }} \text { and } 3^{\text {rd }} \text { order } \\
\text { bandpass filters were fabricated using microstrip technology on Roger } 3210 \\
\text { substrate with parameter of } \varepsilon r=10.2, h=1.27 \text { mm and tan } \delta=3 \times 10-3 \text {. } \\
\text { The filters were measured and the results show good agreement with } \\
\text { simulation results. }\end{array}$} \\
\hline Received Sep 24, 2018 & \\
\hline Revised Dec 7, 2019 & \\
\hline Accepted Dec 13, 2019 & \\
\hline Keywords: & \\
\hline Bandpass filter & \\
\hline Coupled-line & \\
\hline Cross coupling & \\
\hline Narrowband & \\
\hline Tranmission zero & \\
\hline
\end{tabular}

Copyright $@ 2020$ Institute of Advanced Engineering and Science. All rights reserved.

\section{Corresponding Author:}

Mohd Nasiruddin Hushim,

Faculty of Electrical Engineering,

Universiti Teknologi MARA,

40450 Shah Alam, Selangor, Malaysia.

Email: nasiruddin_my@ieee.org

\section{INTRODUCTION}

Rapid developments in wireless communications devices and systems lead to rigorous of high-end electronic devices. These demands created to the high-end research area and fast developments environment to produce high performance electronic circuits and devices. This influenced the filter designs especially at the front-end devices to accommodate the requirements in achieving better selection, good responses without sacrificing the cost and compactness.

The conventional parallel coupled-line filter topology was introduced by Cohn [1] in 1937 and are still being used until today in modern telecommunication systems. The designs varies depending on the requirement, technology and specifications [2-6]. Further researches and enhancements of the coupledline structure still going on until today [7-9]. The passband response of the coupled-line topology depends so much on the number of coupled-line sections connected to the basic topology of the coupled-line. As the degree of orders increased, the number of coupled-line sections need to be increased. As a result, the length of the filter will be increased [10-12]. Furthermore, the arrangement of the coupled-lines sections are arranged in parallel, hence there is no cross coupling effect between the resonators to produce transmission zero [13-15]. In this paper, a new concept of coupled-line resonator is proposed where two shorted quarter-wavelength coupled-line sections are inter-connected to form a bandpass filter response. This topology produced a half-wavelength resonator to form a single resonance. The interesting part of this concept is when additional shorted coupled section is introduced and inter-connected to the existing two coupled-line sections. 
This newly arrangement formed two half wave-length resonators to produce a $2^{\text {nd }}$ order bandpass filter response. With this arrangement, there are cross coupling effects between the resonators which resulted to the occurrence of transmission zero at the lower stopband. With the presence of transmission zero, the $2^{\text {nd }}$ order bandpass filter become more selective as compared to the conventional parallel coupled-line filter. The same technique is applied for $3^{\text {rd }}$ order bandpass filter whereby an additional quarter wavelength coupled-line is cascaded to the $2^{\text {nd }}$ order filter design.

For the development of the resonators with a specific center frequency, fo, the impedance level of the shorted coupled-line section need to be determined. Hence, a basic synthesis of a shorted coupled-line is presented in this paper. From this basic synthesis, further development of synthesis for the $2^{\text {nd }}$ and $3^{\text {rd }}$ order filters are also presented in this paper. Finally, to verify the proposed idea, two bandpass filters up to $3^{\text {rd }}$ order are realized using full wave electromagnetic simulator, fabricated using microstrip technology. The filters are measured and comparison are made with simulated results.

\section{FILTER TOPOLOGY}

A two shorted coupled-lines are inter-connected to form a side-coupled shorted half-wavelength resonator as shown in Figure 1(a). In this configuration, two coupled-lines are inter-connected to create a single resonance bandpass filter with the first coupled-line having impedances of $Z_{o e l}$ and $Z_{o o l}$ whereas the second coupled-line has the impedances of $Z_{o e 2}, Z_{o o 2}$. This topology is used as a base cell to develop higher order filters by interconnecting $\mathrm{n}$ numbers of coupled-lines to the basic cell. The $Z_{o e}$ and $Z_{o o}$ of the coupled-lines are the controlling parameters to achieve desired electrical responses of bandpass filter in terms of bandwidth and insertion loss so that the resonator resonates at a given center frequency, $f_{0}$. The resonance frequency can be controlled easily by varying the length of coupled-lines whereas the insertion and return loss can be controlled by varying the width and gap of the coupled-lines. However, the tolerance of coupling gap is the crucial issue in the coupled-line resonator [16]. To illustrate the concept, the side-coupled shorted half-wavelength resonator is simulated using full-wave electromagnetic simulation tool. The impedances of the first coupled-line are set at $Z_{o e l}=65 \Omega, Z_{o o l}=43 \Omega$, whereas the second coupled-line are $Z_{o e 2}=72 \Omega$ and $Z_{o o 2}=48 \Omega$. As illustrated in Figure 1(b), the ideal response of the filter shown a single resonance at $f_{0}=1 \mathrm{GHz}$ with bandpass filter response.

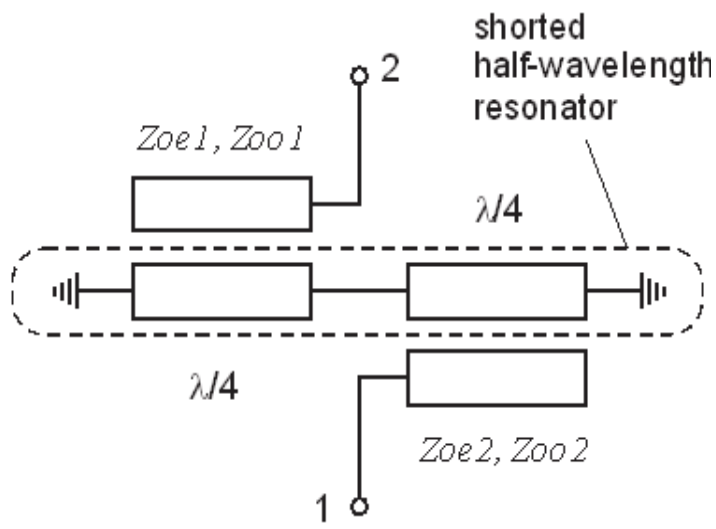

(a)

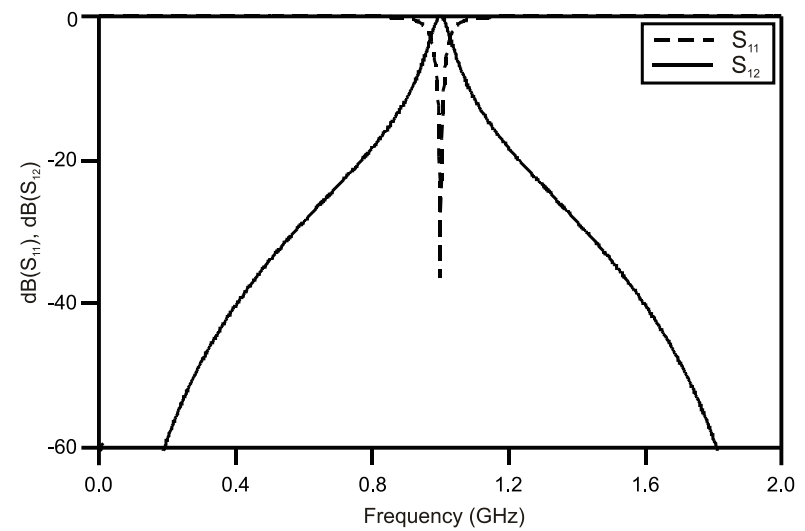

(b)

Figure 1. Side-coupled shorted half wavelength filter, (a) Schematic, (b) Ideal frequency response

To further explore the concept, a third coupled-line is added, inter-connected at the second coupled-line of the basic cell. In this new arrangement, additional of one half wavelength resonator is created. All the impedances of the coupled-lines are optimized to achieve an acceptable bandpass filter response. This newly configuration gives a symmetrical layout arrangement of a bandpass filter of $2^{\text {nd }}$ order filter. Figure 2(a) shows the ideal circuit of the $2^{\text {nd }}$ order bandpass filter response, resonate at $1 \mathrm{GHz}$ with the value of the impedances of the coupled-lines are given by $Z_{o e l}=87 \Omega, Z_{o o l}=43 \Omega, Z_{o e 2}=47 \Omega$ and $Z_{o o 2}=37 \Omega$. For $3^{\text {rd }}$ order bandpass filter topology, another one half wavelength resonator is created by inter-connected one shorted coupled-line into $2^{\text {nd }}$ order topology. All the impedances are optimized to obtain the $3^{\text {rd }}$ order bandpass filter response as shown in Figure 2(b). 
This proposed concept can be seen as $n+1$ quarter wave-length coupled-line sections inter-connected to form $n$th order bandpass filter response. An example of $5^{\text {th }}$ order bandpass filter is illustrated in Figure 3. Quarter wave-length coupled-line sections are added and inter-connected to each other with impedances of $Z_{o e l}=65 \Omega, Z_{o o l}=40 \Omega, Z_{o e 2}=94 \Omega, Z_{o o 2}=32 \Omega \quad Z_{o e 3}=72 \Omega$ and $Z_{o o 3}=50 \Omega$ are set. The response showed an ideal case in achieving return loss of greater than $20 \mathrm{~dB}$. However, as we go for higher order filter design, the gap of coupled-line sections becoming very small; which is less than $0.2 \mathrm{~mm}$ and therefore difficult to realize using microstrip technology. Next, the impedance values of the shorted coupled-lines can be determined through their parametric study by using coupled-line equivalent circuit and transformation [3, 17-19].

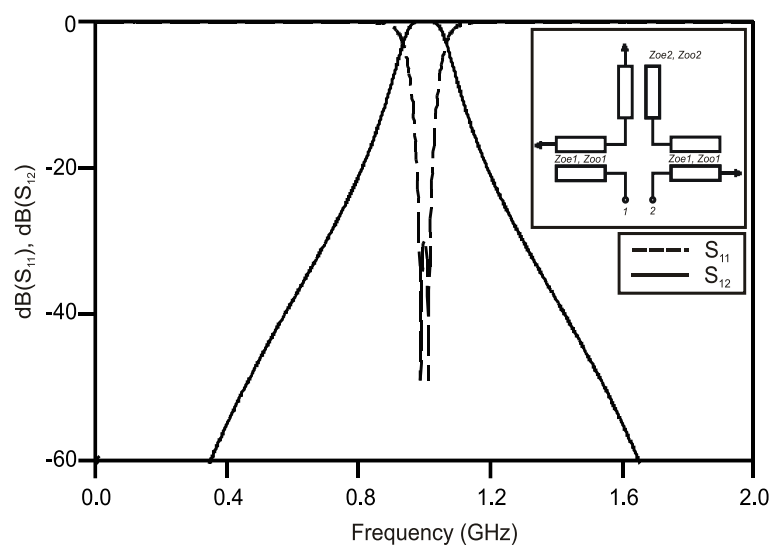

(a)

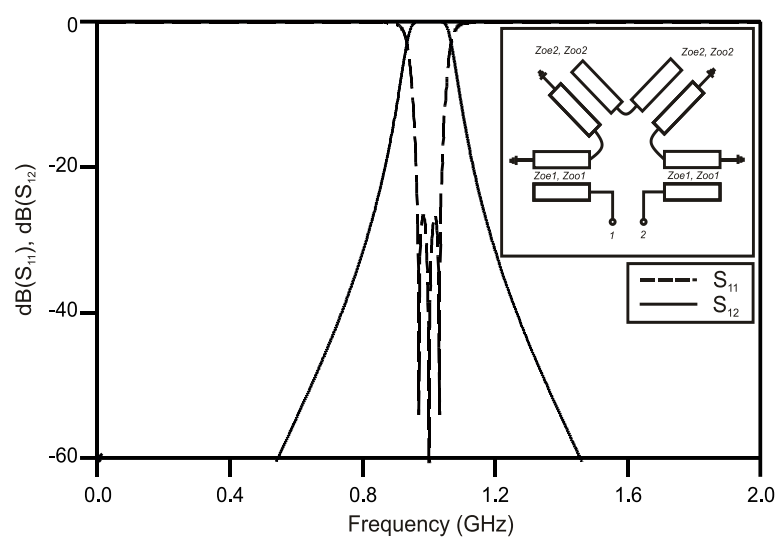

(b)

Figure 2. Schematic \& frequency response of the side-coupled shorted bandpass filter, (a) A $2^{\text {nd }}$ order filter, (b) A $3^{\text {rd }}$ order filter with impedances of $Z_{o e l}=63 \Omega, Z_{o o l}=24 \Omega, Z_{o e 2}=46 \Omega$ and $Z_{o o 2}=35 \Omega$

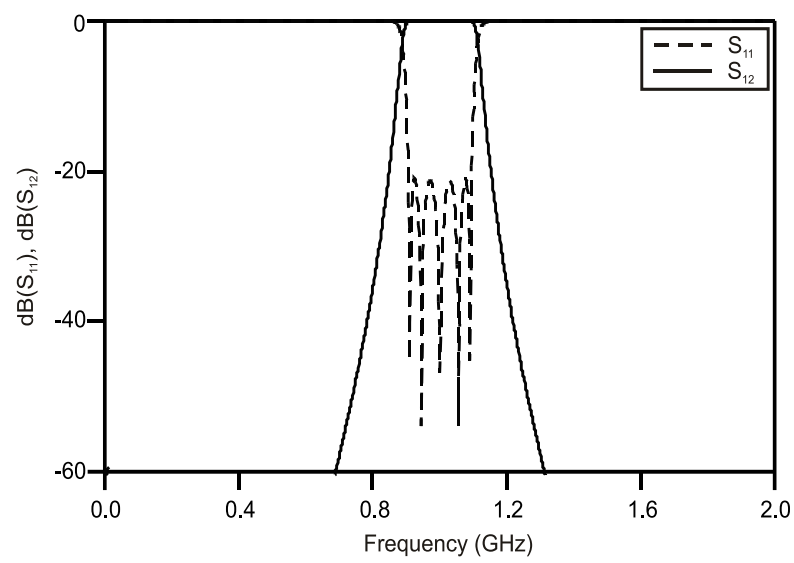

Figure 3. Frequency response of the $\mathrm{N}^{\text {th }}$ order side-coupled shorted bandpass filter

\section{SIDE SHORTED COUPLED-LINE RESONATOR SYNTHESIS}

\subsection{Determination of single shorted coupled-line section}

Based on the definitions and parameters of the side short-circuit of two-port coupled-line in [3], a single shorted coupled-line graph equivalent circuit can be represented as shown in Figure 4. The coupledline network with 2-port and one end short-circuited to ground can be defined in terms of capacitance, $C$, transformer, $T$ and inductance, $L$ in its equivalent circuit. These basic elements are used for the development of the circuit synthesis of this newly proposed resonator. 


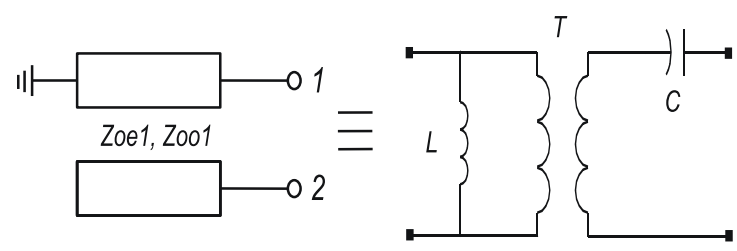

Figure 4. Equivalent circuit diagram of a single shorted two-port coupled-line section

By using the network transformations in [17, 18], the definition of the basic elements are defined and presented in (1)-(3).

$$
\begin{aligned}
& T=\frac{Y_{11}}{Y_{12}} \\
& L=Y_{11}-\frac{Y_{12}{ }^{2}}{Y_{22}} \\
& C=Y_{22}
\end{aligned}
$$

To develop the synthesis of side shorted coupled-line resonator, the equivalent circuit diagram in Figure 4 is used, where

$$
\begin{aligned}
& s=j \tan \theta \\
& \theta=\frac{1}{2} \frac{\pi f r e q}{f_{0}} \\
& Z_{\text {иe }}=\frac{1}{Y_{\text {иe }}} \\
& Y_{\text {оo }}=\frac{1}{Z_{o o}} \\
& Y_{o е}=\frac{1}{Z_{o e}} \\
& Y_{\text {ие }}=Y_{11}-\frac{Y_{12}{ }^{2}}{Y_{11}} \\
& Y_{11}=\frac{Y_{o o}+Y_{o e}}{2} \\
& Y_{12}=\frac{Y_{o o}-Y_{o e}}{2} \\
& T=\frac{Y_{11}}{Y_{12}} \\
& I S=\frac{1}{\sqrt{-s^{2}+1}}
\end{aligned}
$$


Next, the equivalent circuit of Figure 4 is transformed into ABCD matrix as shown is Figure 5.

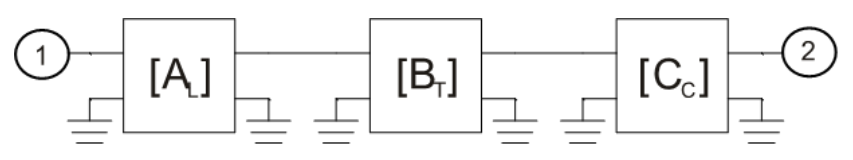

Figure 5. ABCD matrices for single shorted coupled-line section

where,

$A_{L}: A B C D$ Parameter of shunt inductor

$\mathrm{B}_{\mathrm{T}}$ : ABCD Parameter of transformer

$\mathrm{C}_{\mathrm{C}}$ : $\mathrm{ABCD}$ Parameter of series capacitor

$$
\begin{aligned}
& A_{L}=\left[\begin{array}{cc}
1 & 0 \\
\frac{1}{s Z_{\text {ие }}} & 1
\end{array}\right] \\
& B_{T}=\left[\begin{array}{ll}
T & 0 \\
0 & \frac{1}{T}
\end{array}\right] \\
& C_{C}=\left[\begin{array}{cc}
1 & \frac{1}{s Y_{11}} \\
0 & 1
\end{array}\right]
\end{aligned}
$$

By cross product of the ABCD matrices in (14)-(16), the ABCD matrices in Figure 5 can now be seen as one single matrix, $M_{S C}$ as shown in Figure 6 with matrix presentation as in (17)-(20).

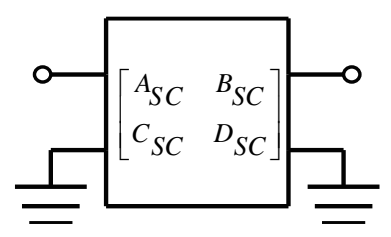

Figure 6. Single matric $\left[M_{S C}\right]$ for single shorted coupled-line section

$$
\begin{aligned}
& A_{S C}=\frac{Z_{o e 1}+Z_{o o 1}}{Z_{o e 1}-Z_{o o 1}} \\
& B_{S C}=2 \frac{Z_{o o 1} Z_{o e 1}}{\left(Z_{o e 1}-Z_{o o 1}\right) j}(\tan \theta)^{-1} \\
& C_{S C}=2 \frac{1}{\left(Z_{o e 1}-Z_{o o 1}\right) j}(\tan \theta)^{-1} \\
& D_{S C}=4 \frac{Z_{o o 1} Z_{o e 1}}{\left(Z_{o e 1}-Z_{o o 1}\right)\left(Z_{o e 1}+Z_{o o 1}\right) j^{2}}(\tan \theta)^{-2}+\frac{Z_{o e 1}-Z_{o o 1}}{Z_{o e 1}+Z_{o o 1}}
\end{aligned}
$$

\section{2. $2^{\text {nd }}$ order bandpass filter}

Based on the single shorted coupled-line section equivalent circuit and its single matrix, $M_{s c}$, the synthesis for $2^{\text {nd }}$ order bandpass filter is developed. As shown in Figure 7, the equivalent circuit of the three shorted coupled-line sections are cascaded forming three matrices. These matrices are 
inter-connected as illustrated in Figure 8. Since the layout of the $2^{\text {nd }}$ order filter is symmetrical, we propose to have same set of impedances, $Z_{o e l}, Z_{o o l}$; for first and third coupled-line sections with matrix represent as $M_{S C 1}$. Whereas for second couple line section, the impedances of $M_{S C 2}$ are $Z_{o e 2}$ and $Z_{o o 2}$.

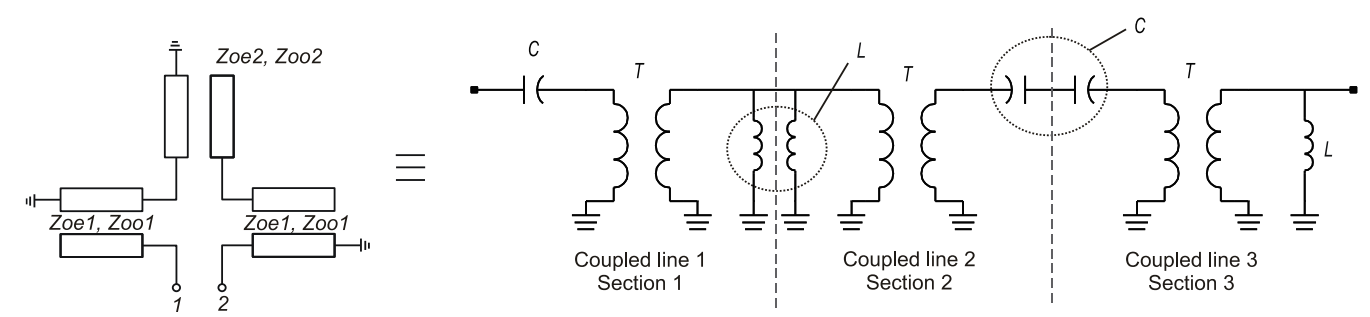

Figure 7. Equivalent circuit diagram of $2^{\text {nd }}$ order bandpass filter

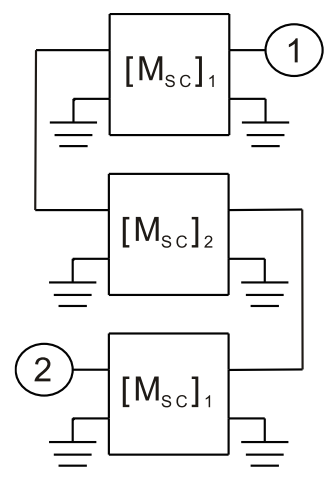

Figure 8. ABCD matrices of the $2^{\text {nd }}$ order bandpass filter

The inter connection of the ABCD matrices in Figure 8 , causing the $\left[M_{S C}\right]_{1}$ and $\left[M_{S C}\right]_{3}$ to be inversed. By cross product all the matrices, the single matrix is obtained. Finally, this matrix is converted to S-Parameters and are derived in (21) and (22) as shown below;

$$
\begin{aligned}
& S_{11}=\frac{R Z_{O}+S-\left(Z_{O}\right)^{2} T-U Z_{O}}{R Z_{O}+S+\left(Z_{O}\right)^{2} T+U Z_{O}} \\
& S_{12}=2 \frac{Z_{0}(R U-S T)}{R Z_{0}+S+\left(Z_{0}\right)^{2} T+U Z_{0}}
\end{aligned}
$$

where

$$
\begin{aligned}
& L=\frac{Z_{o e 2}-Z_{o o 2}}{Z_{o e 2}+Z_{o o 2}}-4 \frac{Z_{o o 2} Z_{o e 2}}{\left(Z_{o e 2}+Z_{o o 2}\right)(\tan (\theta))^{2}\left(Z_{o e 2}-Z_{o o 2}\right)} \\
& M=\frac{Z_{o e 1}-Z_{o o 1}}{Z_{o e 1}+Z_{o o 1}}-4 \frac{Z_{o o 1} Z_{o e 1}}{\left(Z_{o e 1}+Z_{o o 1}\right)(\tan (\theta))^{2}\left(Z_{o e 1}-Z_{o o 1}\right)} \\
& N=\frac{\left(Z_{o e 1}+Z_{o o 1}\right) L}{Z_{o e 1}-Z_{o o 1}}-4 \frac{Z_{o o 1} Z_{o e 1}}{\left(Z_{o e 1}-Z_{o o 1}\right)(\tan (\theta))^{2}\left(Z_{o e 2}-Z_{o o 2}\right)} \\
& O=2 \frac{\left(Z_{o o 1}+Z_{o o 1}\right) Z_{o o 2} Z_{o e 2}}{\left(Z_{o e 1}-Z_{o o 1}\right)\left(Z_{o e 2}-Z_{o o 2}\right) j \tan (\theta)}+2 \frac{Z_{o o 1} Z_{o e 1}\left(Z_{o e 2}+Z_{o o 2}\right)}{\left(Z_{o e 1}-Z_{o o 1}\right)\left(Z_{o e 2}-Z_{o o 2}\right) j \tan (\theta)}
\end{aligned}
$$




$$
\begin{aligned}
& P=\frac{L}{\left(Z_{o e 1}-Z_{o o 1}\right) j \tan (\theta)}+\frac{M}{\left(Z_{o e 2}-Z_{o o 2}\right) j \tan (\theta)} \\
& Q=\frac{M\left(Z_{o e 2}+Z_{o o 2}\right)}{Z_{o e 2}-Z_{o o 2}}-4 \frac{Z_{o o 2} Z_{o e 2}}{\left(Z_{o e 1}-Z_{o o 1}\right)(\tan (\theta))^{2}\left(Z_{o e 2}-Z_{o o 2}\right)} \\
& R=\frac{N\left(Z_{o e 1}+Z_{o o 1}\right)}{Z_{o e 1}-Z_{o o 1}}+2 \frac{O}{\left(Z_{o e 1}-Z_{o o 1}\right) j \tan (\theta)} \\
& S=2 \frac{N Z_{o o 1} Z_{o e 1}}{\left(Z_{o e 1}-Z_{o o 1}\right) j \tan (\theta)}+O M \\
& T=2 \frac{P\left(Z_{o e 1}+Z_{o o 1}\right)}{Z_{o e 1}-Z_{o o 1}}+2 \frac{Q}{\left(Z_{o e 1}-Z_{o o 1}\right) j \tan (\theta)} \\
& U=4 \frac{P Z_{o o 1} Z_{o e 1}}{\left(Z_{o e 1}-Z_{o o 1}\right) j \tan (\theta)}+Q M
\end{aligned}
$$

The S-Parameters of $S_{11}$ and $S_{12}$ in (21) and (22) respectively can only be applied for this $2^{\text {nd }}$ order resonator for a given center frequency.

\section{3. $3^{\text {rd }}$ order bandpass filter}

The $3^{\text {rd }}$ order bandpass filter is constructed based on the $2^{\text {nd }}$ order equivalent circuit as in Figure 7. A new section of shorted coupled-line is cascaded and connected after section 3 as shown in Figure 9 for $3^{\text {rd }}$ order bandpass filter circuit. The arrangement of ABCD matrix is developed by a combination of four matrices $\left(M_{S C}\right)$ as shown in Figure 10.

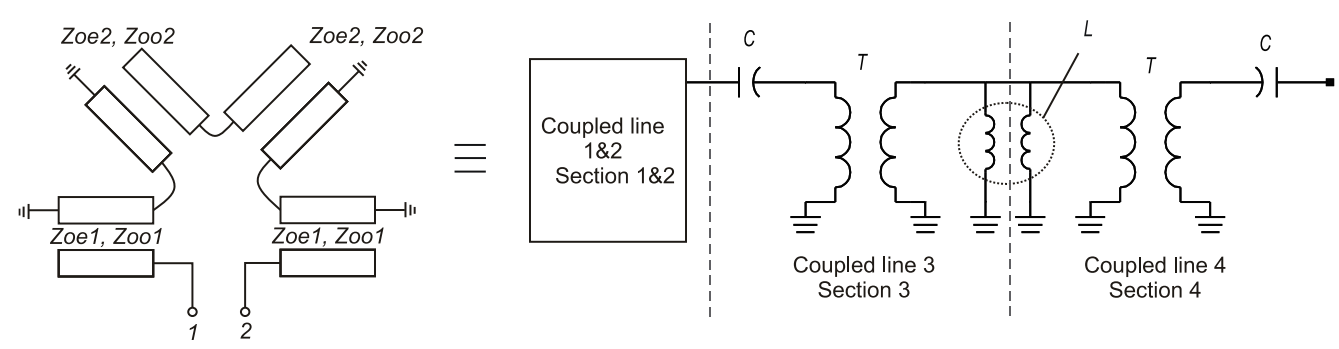

Figure 9. Equivalent circuit diagram of $3^{\text {rd }}$ order bandpass filter

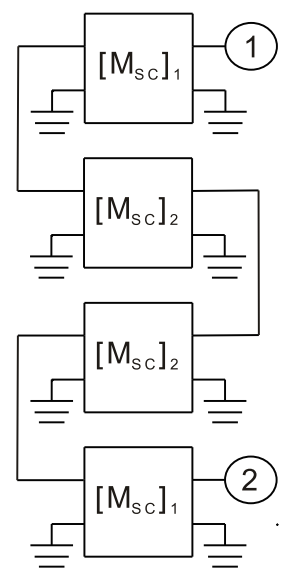

Figure 10. $\mathrm{ABCD}$ matrices of the $3^{\text {rd }}$ order bandpass filter 
By cross product all the matrices, S-Parameters for $3^{\text {rd }}$ order bandpass filter are obtained and the derivation of the parameters are as shown in (33) and (34).

$$
\begin{aligned}
& S_{11}^{2}=\frac{\left(Z_{o}\right)^{2} K_{2} M_{2}-L_{2} N_{2}}{\left(Z_{o}\right)^{2} K_{2} M_{2}+Z_{o} N_{2} K_{2}+Z_{o} L_{2} M_{2}+L_{2} N_{2}} \\
& S_{12}^{2}=Z_{o} \frac{N_{2} K_{2}-L_{2} M_{2}}{\left(Z_{o}\right)^{2} K_{2} M_{2}+Z_{o} N_{2} K_{2}+Z_{o} L_{2} M_{2}+L_{2} N_{2}}
\end{aligned}
$$

where,

$$
\begin{aligned}
E= & \tan \left(1 / 2 \frac{\pi f r e q}{F o}\right) \\
F_{2}= & 4 \frac{Z_{o o 2} Z_{o e 2}}{\left(Z_{o e 2}+Z_{o o 2}\right) j^{2} E^{2}\left(Z_{o e 2}-Z_{o o 2}\right)}+\frac{Z_{o e 2}-Z_{o o 2}}{Z_{o e 2}+Z_{o o 2}} \\
G_{2}= & 4 \frac{Z_{o o 1} Z_{o e 1}}{\left(Z_{o e 1}+Z_{o o 1}\right) j^{2} E^{2}\left(Z_{o e 1}-Z_{o o 1}\right)}+\frac{Z_{o e 1}-Z_{o o 1}}{Z_{o e 1}+Z_{o o 1}} \\
K_{2}= & \frac{F_{2}\left(Z_{o e 1}+Z_{o o 1}\right)}{Z_{o e 1}-Z_{o o 1}}+4 \frac{Z_{o o 2} Z_{o e 2}}{\left(Z_{o e 2}-Z_{o o 2}\right) j^{2} E^{2}\left(Z_{o e 1}-Z_{o o 1}\right)} \\
L_{2}= & 2 \frac{F_{2} Z_{o o 1} Z_{o e 1}}{\left(Z_{o e 1}-Z_{o o 1}\right) j E}+2 \frac{Z_{o o 2} Z_{o e 2} G_{2}}{\left(Z_{o e 2}-Z_{o o 2}\right) j E} \\
M_{2}= & \frac{2 Z_{o e 1}+2 Z_{o o 1}}{\left(Z_{o e 2}-Z_{o o 2}\right) j E\left(Z_{o e 1}-Z_{o o 1}\right)} \\
& +\frac{2 Z_{o e 2}+2 Z_{o o 2}}{\left(Z_{o e 2}-Z_{o o 2}\right) j E\left(Z_{o e 1}-Z_{o o 1}\right)} \\
N_{2}= & 4 \frac{Z Z_{o o 1} Z_{o e 1}}{\left(Z_{o e 2}-Z_{o o 2}\right) j^{2} E^{2}\left(Z_{o e 1}-Z_{o o 1}\right)}+\frac{\left(Z_{o e 2}+Z_{o o 2}\right) G_{2}}{Z_{o e 2}-Z_{o o 2}}
\end{aligned}
$$

\section{4. $2^{\mathrm{ND}}$ AND $3^{\mathrm{RD}}$ ORDER FILTER REALIZATION}

For validation of the proposed concept, the $2^{\text {nd }}$ order and $3^{\text {rd }}$ order resonators are realized using microstrip technology substrate RO3210 substrate with characteristics are given as $h=1.27 \mathrm{~mm}, \mathcal{E}_{r}=10.2$, $\tan \delta=3 \times 10^{-3}$. The layout with dimensions of $2^{\text {nd }}$ order microstrip resonator is as shown in Figure 11(a) and the photograph of the resonator with size of $48 \mathrm{~mm} \mathrm{X} 40 \mathrm{~mm}$ is as shown in Figure 11(b). As shown in Figure 11(a), the gap of two coupled-lines are very small causing tight coupling effect. In terms of electrical response, this lead to low insertion loss.

The simulated and measurement S-parameters responses of the $2^{\text {nd }}$ order resonator are shown in Figure 12. We may note that, the frequency for measured result is slightly shifted as compared to the simulation. The center frequency of the measured result is about $2.043 \mathrm{GHz}$ whereas for the simulation is found up at $2.0 \mathrm{GHz}$. This shifted frequency which is around $2.15 \%$ shifted may be due to the value of the dielectric constant of the substrate used. The measured result shows a $2^{\text {nd }}$ order response with FBW of $5.5 \%$, whereas return loss attenuated more than $18 \mathrm{~dB}$ and insertion loss is less than $3 \mathrm{~dB}$. The significant of this design is that the measured response had shown a transmission zero at the lower side band. This is due to the cross coupling effect of the adjacent coupled-line sections.

For the $3^{\text {rd }}$ order bandpass filter, the layout is depicted in Figure 13(a) as the coupled-line are arranged nearly side-by-side surrounding an axis. The immediate advantage of this arrangement is the overall length of the filter. The $3^{\text {rd }}$ order filter is simulated and measurement results are depicted in Figure 14. The narrow bandpass filter with 5.5\% relative bandwidth, the in-band insertion loss is found to be less than 3 $\mathrm{dB}$ and the return loss more than $15 \mathrm{~dB}$. Furthermore, a transmission zeros are found at the upper and lower 
stopband due to the cross coupling effect between the resonator in the star arrangement inter-connected. Finally, the proposed topologies are compared with other published works, as tabulated in Table 1. We observed that the proposed concept has advantages in terms of availability of synthesis, exhibit transmission zero and narrow bandwidth of less than $6 \%$ compared to others.

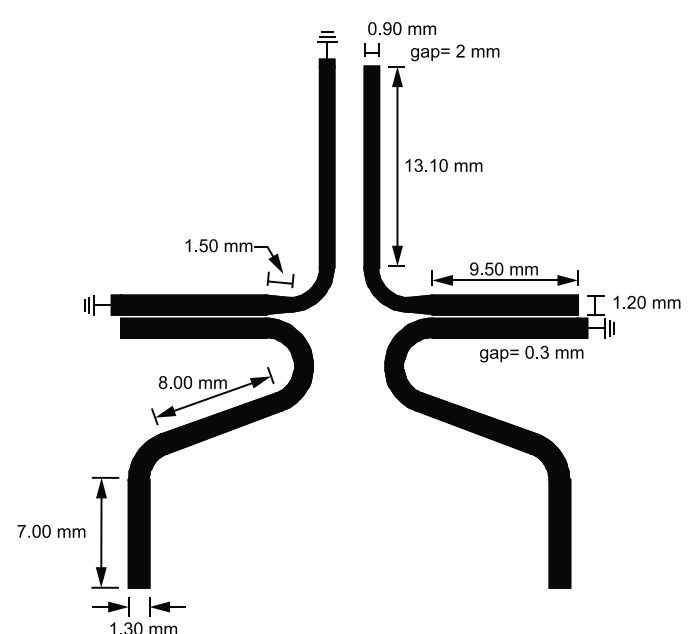

(a)

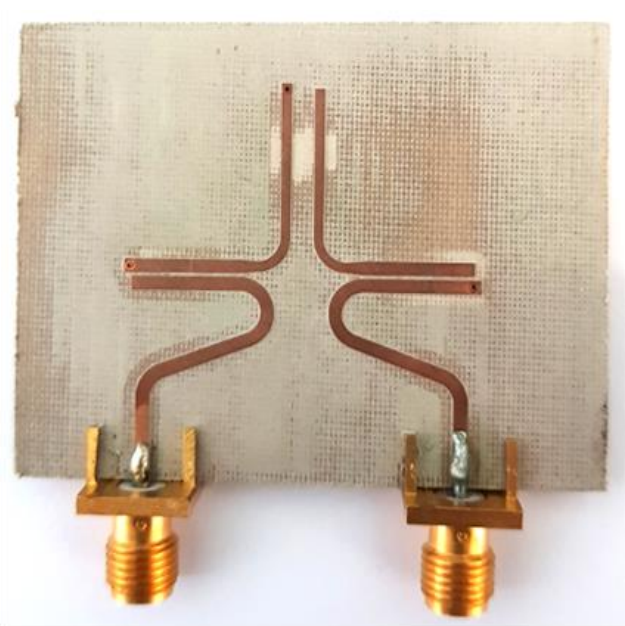

(b)

Figure 11. A $2^{\text {nd }}$ order bandpass filter, (a) Schematic layout, (b) Photograph

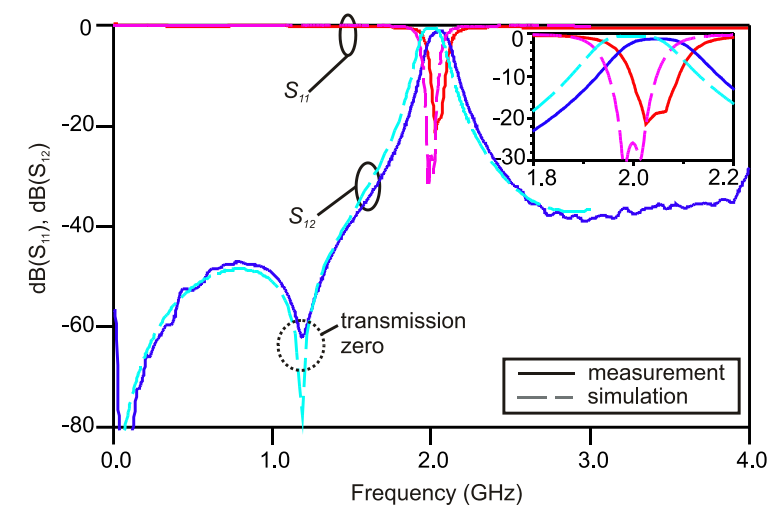

Figure 12. Measurement results of the $2^{\text {nd }}$ order bandpass filter

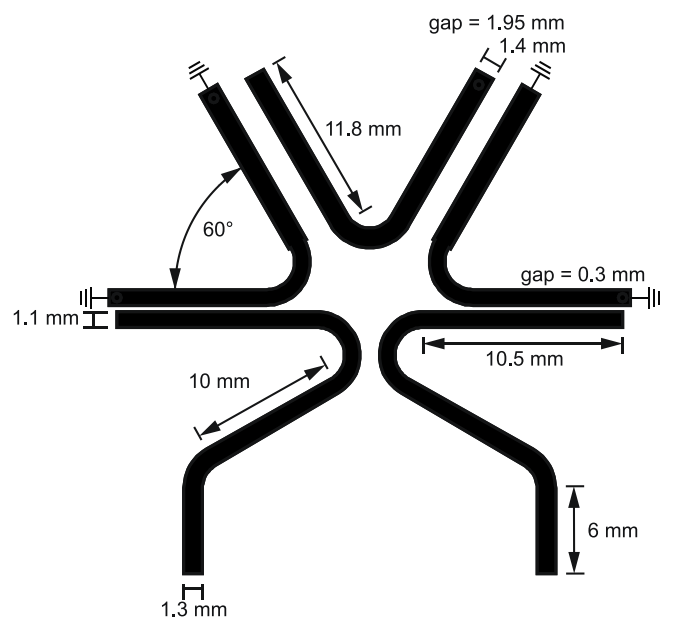

(a)

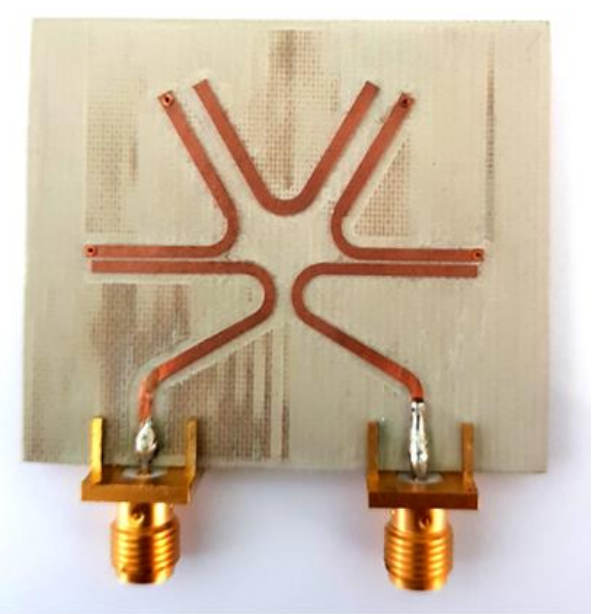

(b)

Figure 13. A 3rd order bandpass filter, (a) Schematic layout, (b) Photograph 


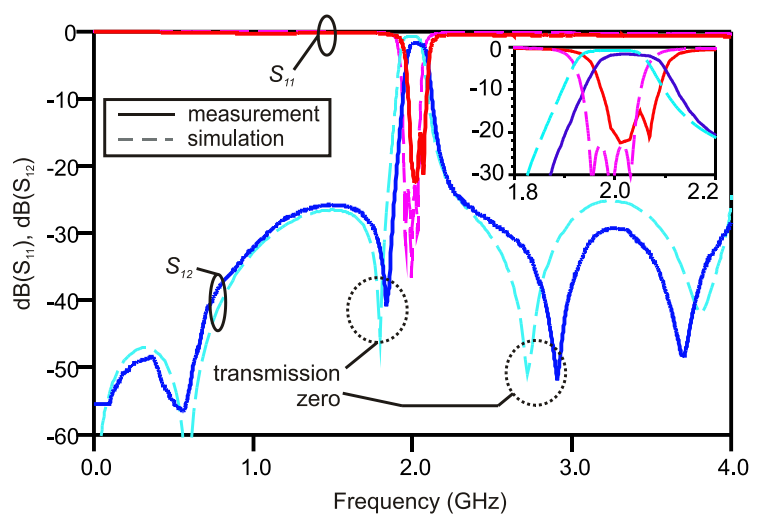

Figure 14. Measurement results of the $3^{\text {rd }}$ order bandpass filter

Table 1. Comparison with other related works

\begin{tabular}{|c|c|c|c|}
\hline Ref. & Synthesis & Transmission Zero & Bandwidth \\
\hline [20] & Yes & No & $10 \%$ \\
\hline [21] & Yes & No & $50 \%$ \\
\hline [22] & No & Yes & $5.69 \%$ \\
\hline [23] & No & Yes & $80 \%$ \\
\hline [24] & No & Yes & $98.73 \%$ \\
\hline [25] & No & Yes & $52.17 \%$ \\
\hline [26] & No & No & $18.18 \%$ \\
\hline \multirow{2}{*}{ This work } & $\begin{array}{c}\text { Yes } \\
\left(2^{\text {nd }} \text { order }\right)\end{array}$ & Yes & $5.5 \%$ \\
\hline & $\begin{array}{c}\text { Yes } \\
\left(3^{\text {rd }} \text { order }\right)\end{array}$ & Yes & $5.5 \%$ \\
\hline
\end{tabular}

\section{CONCLUSION}

The bandpass filters based on quarter wavelength shorted coupled-line resonator were presented. As the side shorted coupled-line sections topology support narrow bandwith with transmission zeros in their frequency responses, compact and selective narrow bandpass filters maybe realized. The order of the filter can be increased by inter-connecting the number of the shorted coupled-line sections as described in the paper. The way the inter-connected of the coupled-lines in star-connection arrangement optimized the surface area of the filter, as compared to traditional way of parallel coupled-lines filter. Furthermore, the adjacent coupled-lines which are found to be very close to each other contribute to the occurrence of cross coupling effect which giving birth to transmission zeros. These transmission zeros are found near to the passband which ultimately improved the selectivity of the filter. Finally, the $2^{\text {nd }}$ and $3^{\text {rd }}$ order microstrip bandpass filter topologies were validated, where the measurement results were found in good agreement with the simulations results.

\section{ACKNOWLEDGEMENTS}

The authors gratefully acknowledge the contributions of M. K. M. Salleh, who passed away in September 2017, for his patience, motivation, support and guidance on this work. This work was supported in part by the Ministry of Higher Education of Malaysia (MOHE) (Grant no: 600-RMI/NRGS 5/3 (3/2013)) and the Institute of Research Management and Innovation (IRMI) of Universiti Teknologi MARA.

\section{REFERENCES}

[1] S. B. Cohn, "Parallel-Coupled Transmission-Line-Resonator Filters," IRE Trans. Microw. Theory Tech., vol. 6(2), pp. 223-231, 1958.

[2] Y. Wu, et al., "Wideband filtering power divider based on coupled-lines and short-circuited stubs," in 2016 IEEE International Conference on Ubiquitous Wireless Broadband (ICUWB), vol. 1, pp. 1-3, 2016.

[3] G. L. Matthaei, Microwave Filters, Impedance Matching network and Coupling Structure, Artech House, Norwood, MA, 1964.

[4] A. K. Gorur, "A Novel Compact Microstrip Balun Bandpass Filter Design Using Interdigital Capacitor Loaded Open Loop Resonators," Prog. Electromagn. Res. Lett., vol. 76(January), pp. 47-53, 2018. 
[5] N. A. Wahab, et al., "Synthesis of a Single Side Access Ring Resonator for Higher Order Bandpass Filter," Prog. Electromagn. Res. Lett., vol. 38(March), pp. 137-150, 2013.

[6] J. Hong and M. J. Lancaster, Microstrip Filters for RF / Microwave, vol. 7, 2001.

[7] E. G. Sahin, et al., "Design of Wideband Bandpass Filters Using Parallel- Coupled Asymmetric Three Line Structures with Adjustment Elements," Proc. 49th Eur. Microw. Conf. Des., pp. 464-467, 2019.

[8] M. Naureen, D. K. Choudhary, and R. K. Chaudhary, "Compact metamaterial inspired dual-band bandpass filter using parallel coupled line and circular shaped stub," 2018 3rd Int. Conf. Microw. Photonics, ICMAP 2018, vol. 2018-Jan(Icmap), pp. 1-2, 2018.

[9] T. K. Das and S. Chatterjee, "Spurious Harmonic Suppression in a Folded Parallel- Coupled Microstrip Bandpass Filter by using Triangular Corrugations," 2017 Devices Integr. Circuit, pp. 23-24, 2017.

[10] K. Thirumalaivasan and R. Nakkeeran, "A new ultra-wideband parallel coupled line microstrip bandpass filter," ICECT 2011 - 2011 3rd Int. Conf. Electron. Comput. Technol, vol. 4, pp. 427-429, 2011.

[11] A. E. Ferh and H. Jleed, "Design, simulate and approximate parallel coupled microstrip bandpass filter at $2.4 \mathrm{GHz}, "$ 2014 World Congr. Comput. Appl. Inf. Syst. WCCAIS 2014, pp. 5-9, 2014.

[12] N. N. Al-Areqi, et al., "Parallel-coupled line bandpass filter design using different substrates for fifth generation wireless communication applications," 2015 Int. Symp. Antennas Propagation, ISAP 2015, pp. 3-6, 2016.

[13] Xiongjun Shu, Jincai Wen, and Lingling Sun, "Design of $60 \mathrm{GHz}$ parallel coupled-line bandpass filters," in 2015 IEEE 16th International Conference on Communication Technology (ICCT), pp. 244-247, 2015.

[14] P. B. Saha, S. Roy, and M. Bhowmik, "Improvement of parallel coupled bandpass filter using coupled closed loop square resonator structure," in 2015 2nd International Conference on Signal Processing and Integrated Networks (SPIN), no. c, pp. 65-68, 2015.

[15] A. E. Ferh and H. Jleed, "Design, simulate and approximate parallel coupled microstrip bandpass filter at $2.4 \mathrm{GHz}$," in 2014 World Congress on Computer Applications and Information Systems (WCCAIS), pp. 1-5, 2014.

[16] A. M. Zobilah, A. Othman, N. A. Shairi, and Z. Zakaria, "Parametric studies of ring and parallel coupled line resonators for matched bandstop filter design," Indonesian Journal of Electrical Engineering and Computer Science, vol. 14(1), pp. 29-37, 2019.

[17] R. Sato and E. Cristal, "Simplified Analisis of Coupled Transmision-Line Networks," IEEE Trans. Microw. Theory Tech., vol. 1(3), 1970.

[18] H. Ozaki, and J. Ishii, "Synthesis of a class of strip-line filters," IRE Trans. Circuit Theory, vol. 5(2), pp. 107-114, 1958.

[19] Y. Nemoto, K. Kobayashi, and R. Sato, "Graph tranformations of nonuniform coupled tranmission line network and their application," IEEE Trans. Microw. Theory Tech., vol. 33(1977), pp. 1257-1263, 1985.

[20] C. J. Chen, "Design of Parallel-Coupled Dual-Mode Resonator Bandpass Filters," IEEE Trans. Components, Packag. Manuf. Technol., vol. 6(10), pp. 1542-1548, 2016.

[21] Q. Wu and L. Zhu, "Synthesis design of a wideband impedance transformer consisting of two-section coupled lines," IET Microwaves, Antennas Propag, vol. 11, pp. 144-150, 2017.

[22] C. F. Yang, et al., "Design and Fabrication of a Compact Quadband Bandpass Filter Using Two Different Parallel Positioned Resonators," Prog. Electromagn. Res., vol. 115(March), pp. 159-172, 2011.

[23] L. Li and Z. F. Li, "Side-coupled shorted microstrip line for compact quasi-elliptic wideband bandpass filter design," IEEE Microw. Wirel. Components Lett., vol. 20(6), pp. 322-324, 2010.

[24] Y. Gaurav and R. K. Chauhan, "A Compact UWB BPF with a Notch Band using Rectangular Resonator Sandwiched between Interdigital Structure," International Journal of Electrical and Computer Engineering (IJECE), vol. 7(5), pp. 2420-2425, 2017.

[25] S. Azizi, et al., "Enhanced Bandwidth of Band Pass Filter Using a Defected Microstrip Structure for Wideband Applications," International Journal of Electrical and Computer Engineering (IJECE), vol. 8(6), pp. 5260-5267, 2018.

[26] L. T. Phuong, B. Journet, and D. B. Gia, "A microwave active filter for nanosatellite's receiver front-ends at S-band," International Journal of Electrical and Computer Engineering (IJECE), vol. 9(2), pp. 973-981, 2019.

\section{BIOGRAPHIES OF AUTHORS}

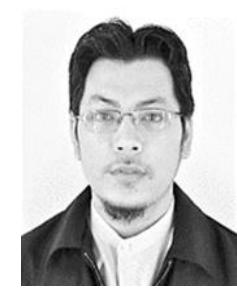

Mohd Nasiruddin Hushim was born in Kuala Lumpur, Malaysia, on February 25, 1982. He received the degree of bachelor in Electrical Engineering from Kolej Universiti Teknologi Tun Hussein Onn, Johor, Malaysia in 2005 and degree of master in Technical and Vocational Education from Universiti Tun Hussein Onn, Johor, Malaysia in 2007. He is currently working toward the Ph.D degree in Electrical Engineering at the Universiti Teknologi Mara Shah Alam, Selangor, Malaysia. His research principally concern the design of passive microwave design. 


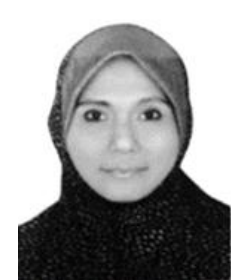

Norfishah Ab Wahab was born in Malaysia, in 1963. She received the degree in Electronics Engineering from Universiti Teknologi MARA (UiTM), Malaysia, MSc in Telecommunication and Information Engineering and $\mathrm{PhD}$ in microwaves, electromagnetism in the same university. Currently, she is a senior lecturer in Faculty of Electrical Engineering, UiTM Shah Alam, Malaysia. She has been working in UiTM since April 2008. From 1992 to 2004, she was employed by Telekom Malaysia. She worked in various divisions such as microwave, fiber cable and network system departments. Her major research areas are in microwave and electromagnetic modeling, low-powered electronic design, energy harvesting and efficiency.

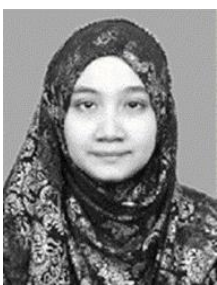

Tuan Syarifah Atifah Tuan Mat Zin was born in Kelantan, Malaysia, on October 21, 1982. She received the Bachelor of Engineering (Hons) and Master Degree of Engineering in Communication and Computer from the Universiti Kebangsaan Malaysia in 2005 and 2018 respectively. Her master research concerned the study of cellular and wireless, especially the spectrum access in licensed and unlicensed band. She is currently a lecturer at Mathematics, Science and Computer department, Politeknik Banting Selangor, Malaysia.

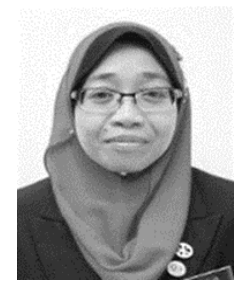

Norlia Ghazali was born in Penang, Malaysia, on May 22, 1981. She received the degree in Electrical Engineering from Universiti Teknologi MARA Shah Alam, Selangor, Malaysia in 2005 and master degree in Technical and Vocational Education from Universiti Tun Hussein Onn, Johor, Malaysia in 2007. She is currently a lecturer at Politeknik Banting Selangor, Malaysia. 